Document downloaded from:

http://hdl.handle.net/10251/62768

This paper must be cited as:

María-Antonia Serrano; J. Cañada; Moreno, J.; Gonzalo Gurrea-Ysasi (2014). Personal UV Exposure for Different Outdoor Sports. Photochemical \&amp; Photobiological Sciences Photochemical and Photobiological Sciences. 13:671-679. doi:10.1039/c3pp50348h.

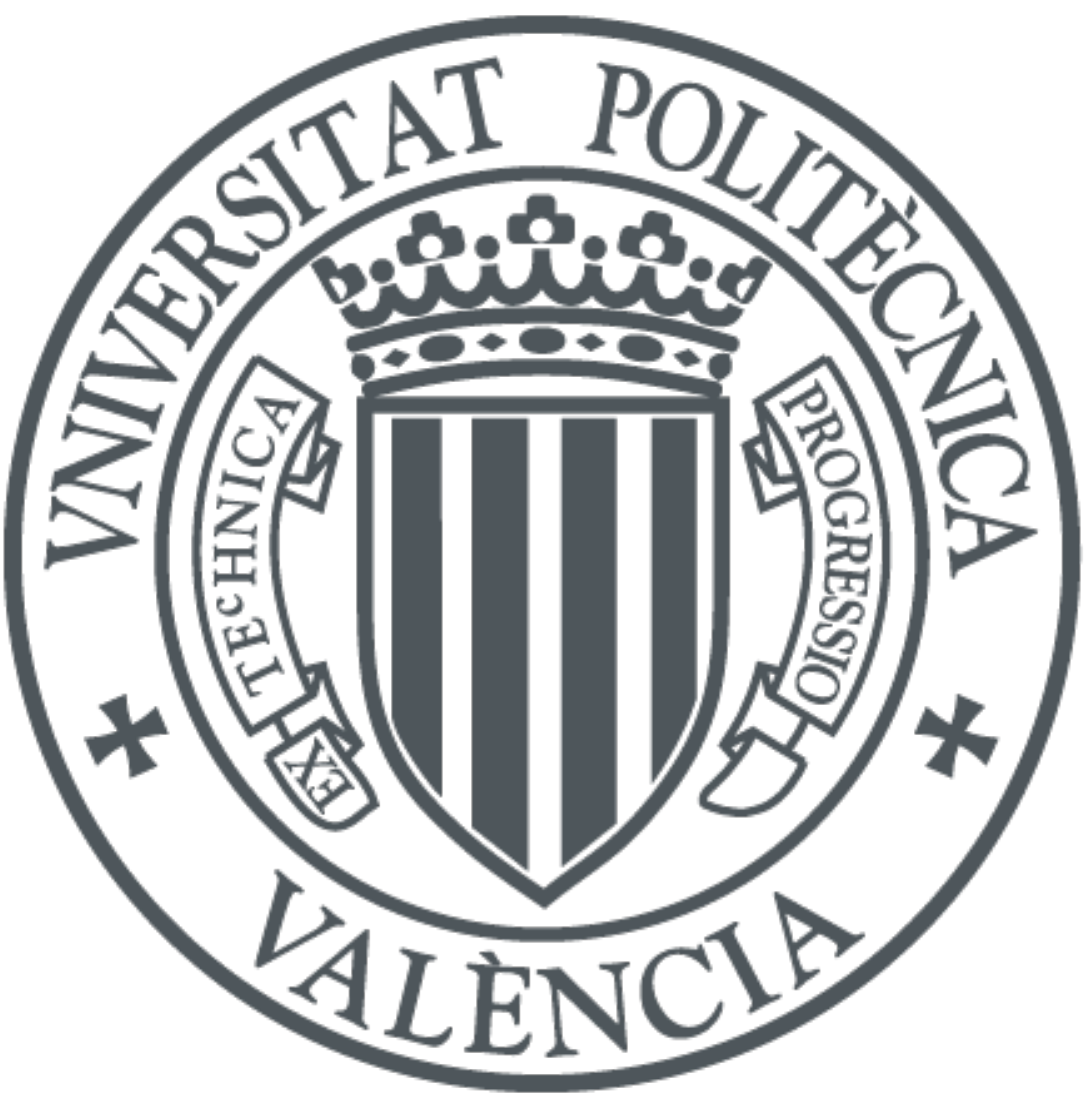

The final publication is available at

http://dx.doi.org/10.1039/c3pp50348h

Copyright Royal Society of Chemistry

Additional Information 


\section{Personal UV Exposure for Different Outdoor Sports.}

María-Antonia Serrano, * Javier Cañada * Juan Carlos Moreno and Gonzalo Gurrea

Instituto de Ingeniería Energética, Universitat Politècnica de València, Camino de Vera s/n, 46022 Valencia, España

Members of the Valencia Solar Radiation Research Group

*Corresponding author: mserranj@ fis.upv.es (Maria Antonia Serrano),

Tel: +34-963877007; Fax: +34-963879896.

The aim of this paper is to measure UV exposure for three groups of amateur athletes in their training/recreational schedules, using VioSpor personal dosimeters and we found that two of these groups exceeded the international UV threshold level for non sun-adapted Mediterranean skin.

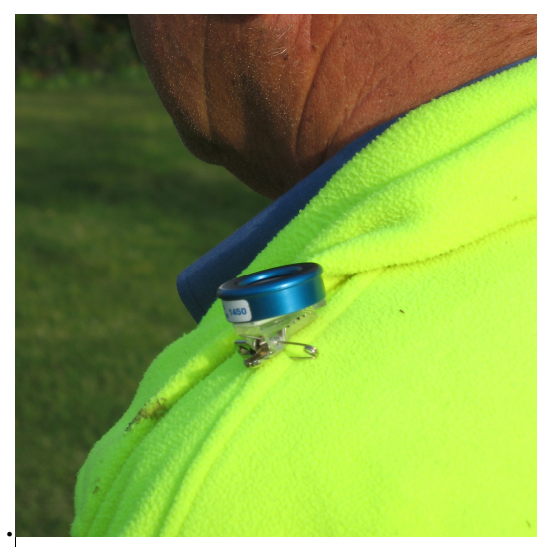

-Professor Dr. Javier Cañada passed away in January when the study was in the development stage. 


\section{Abstract}

Exposure to ultraviolet (UV) radiation is the major environmental risk factor in the development of skin cancers and it occurs mainly during outdoor activities. The purpose of this study is to quantify the UV exposure suffered by amateur athletes (tennis players, hikers and runners) in their training schedules. The study on tennis player exposure took place at a tennis club in Valencia during the month of June 2011. With respect to the hiking group, the hikes studied took place in several mountainous areas of Spain and France from June to August 2011. Finally, the exposure suffered by ten runners, while participating in a running circuit in the province of Valencia, from March to November 2011, was studied. The athletes were monitored using personal dosimeters (VioSpor), with the tennis players and runners wearing them on the wrist, and the hikers on the shoulder. The median daily personal UV exposure for the hikers was 8.1 Standard Erythema Dose (SED), and for the tennis players 7.5 SED, per day of training. The runners received a median of 14.6 SED while participating in the running circuit, and about 2 SED per competition day. Median daily UV exposure of the hikers and tennis players exceeded 5 SED, which means that, in the case of non sun-adapted skin type III and the non-use of sun protection, erythema may be induced in these subjects. However, the exposure suffered by the runners did not exceed the maximum personal exposure of 5 SED. Accordingly, it is necessary to encourage the use of high protection sunscreens and protective clothing, and to avoid UV exposure in the hottest part of the day.

Keywords: Erythemal ultraviolet radiation; UV exposure; personal dosimetry; exposure ratio; VioSpor. 


\section{Introduction}

Ultraviolet solar radiation (UVR) has a significant influence on the health of living beings. Excessive UV exposure is detrimental to individuals, as it can cause erythema, sunburn, and cortical cataracts, among other problems, and appears to be a cause of the development of both melanoma and non-melanoma skin cancers later in life. ${ }^{1-4}$ On the other hand, sun exposure is also beneficial for human health, ${ }^{2,4}$ as appropriate doses give beneficial physiological effects, such as the synthesis of Vitamin $\mathrm{D}, 5,6$ essential for bone mineralization and skeletal health. ${ }^{7}$ It also has beneficial effects with regard to the prevention of several diseases ${ }^{8-11}$ and on mental health. ${ }^{12}$

There is evidence that skin cancer and melanoma represent a public health problem in Spain and the rest of Europe since their incidence has increased significantly in the last 40 years. ${ }^{13-16}$ With respect to melanoma, its incidence has nearly tripled in the last 40 years at a rate of $4 \%$ per year in Europe, ${ }^{17}$ and up to $80 \%$ of all deaths from skin cancers are due to melanoma. ${ }^{3}$ In Spain, the mortality rate from melanoma has quadrupled during the $1975-2008$ period, ${ }^{18}$ although in the last decade only a slight increase in annual mortality has been observed, due to information and prevention campaigns such as Euromelanoma. ${ }^{19}$

Solar UV exposure mainly occurs during outdoor occupational or recreational activities. The practice of sport is highly recommended by health organizations due to its beneficial effects on the cardiovascular system, but it must be borne in mind that sportsmen/women are potentially exposed to excessive doses of solar UVR, especially during training sessions on hot days. Several studies indicating the occurrence of skin melanomas in marathon runners, ${ }^{20,21}$ cyclists, ${ }^{22}$ mountain guides ${ }^{23}$ and golfers ${ }^{24}$ support the idea that participating in outdoor sports can increase the risk of skin cancer. 
The importance of UV radiation and the diseases related to it is demonstrated by the amount of scientific literature devoted to this area, but the growing number of new cases of skin cancer around the world has also led to increasing interest among the groups that are exposed to high levels of solar radiation, with regard to the UV doses they receive in their daily schedules. Therefore, the purpose of this article is to study the UV exposure of different groups of sportsmen and women during their training or recreational schedules. Mountaineering and cycling are among the outdoor recreational activities with the highest measured UV exposure and the largest number of studies. ${ }^{25-31}$ However, there are few studies on the UV exposure of runners ${ }^{28}$ and tennis players ${ }^{28,31}$ while performing their sport.

\section{Materials and methods}

\section{Study location}

Regarding hiking group, they undertook six hikes on $12^{\text {th }} \mathrm{June}, 3^{\text {rd }}, 8^{\text {th }}$ and $9^{\text {th }}$ July and August $11^{\text {th }}$ and $12^{\text {th }} 2011$ (Table 1). The first two hikes took place in two locations 70 to $100 \mathrm{~km}$ away from the city of Valencia. The third hike, lasting two days, was conducted in Cauterets (coordinates $0^{\circ} 6^{\prime} 45^{\prime}{ }^{\prime} \mathrm{W}, 42^{\circ} 53^{\prime} \mathrm{N}$, min.:503 m, max.:3300 m), a commune in the Hautes-Pyrénées department of south-western France. The last hike, also two days in duration, took place on the island of La Palma (coordinates $17^{\circ} 53$ ' W, $28^{\circ} 43$ ' $\mathrm{N}$, highest elevation $2423 \mathrm{~m}$ ) in the Atlantic Ocean, part of the archipelago of the Canary Islands (Spain). During the study period, the range of noon solar zenith angle was between 16.4 and 24.3 degrees. 
The study on tennis player exposure took place at a tennis club in Valencia (coordinates $0^{\circ} 22^{\prime} \mathrm{W}, 39^{\circ} 28^{\prime} \mathrm{N}$, sea level) on $12^{\text {th }}$ and $27^{\text {th }} \mathrm{June} 5^{\text {th }}, 14^{\text {th }}$ and $20^{\text {th }} \mathrm{July}$, 2011. The study took place at the same time on two different tennis courts with different orientations with respect to the sun. The noon solar zenith angle was between 16.4 and 18.7 degrees during the research period.

We also studied the dose received by several runners of the Universitat Politècnica de València (UPV) athletics club, while they participated in a running circuit with races in various municipalities of the province of Valencia, from March to November 2011. These races took place in locations which were 10 to $70 \mathrm{~km}$ away from the city of Valencia. Because the running circuit takes place over several months the range of noon solar zenith angle range is quite wide, from a maximum of 55.4 degrees in November to a minimum of 16.4 degrees in July.

\section{$\langle$ Table1>}

\section{Subjects and design}

Participants taking part in the study included: four subjects from a hiking group; four men (two coaches and two students) from a tennis club; and ten randomly selected subjects (eight men and two women) from the UPV athletics club. Readings were discarded for three of the runners as they finished fewer than 4 races and so could not be considered as representative of the running circuit as a whole.

The subjects filled in a report containing information on the time at which they put on and took off the dosimeter, the number of hours spent outdoors, the type of activity and the weather conditions. They were asked not to change their behaviour during the study and to continue their normal schedule of outdoor activities. 


\section{Personal UV dosimeters}

A VioSpor UV dosimetry system (VioSpor, Bio-Sense, Bornheim, Germany) ${ }^{32}$ was used to measure the UV exposure of these groups of athletes. These dosimeters have been used effectively for personal UV measurements in outdoor occupations, ${ }^{25,33}$ and in recreational activities. ${ }^{28-30}$

Details of the production and development of the spore films (containing DNA molecules of Bacillus subtilis) can be found at Furusawa et al. ${ }^{34}$ and Munakata et al. ${ }^{35}$ The spore films are covered by a filter system with optical properties extremely similar to the erythemal response of human skin according to the International Commission on Illumination (CIE) reference spectrum. ${ }^{36}$ The measurements are expressed as a standard erythema dose (SED), ${ }^{37}$ where 1 SED is defined as an effective erythemal exposure of $100 \mathrm{~J} / \mathrm{m}^{2}$ when weighted with the CIE erythemal spectrum. ${ }^{36}$ The working range used is 0.5-30 SED and the measurement error is $\pm 10 \%$, according to the manufacturer. ${ }^{32}$

The VioSpor system validation is conducted using in-vivo comparative measurements. ${ }^{38}$ The wavelength-specific calibration of VioSpor is performed using measurements on the Okasaki spectrograph in Japan. ${ }^{34,35}$ The conclusions of the paper by Furusawa et al. ${ }^{34}$ were that VioSpor dosimeters are a system tat gives reliable results (with a standard deviation of $12.8 \%$ during the field experiments and below $10 \%$ under laboratory conditions) even at low solar elevation angles, as in our paper, and at longer wavelengths. Furthermore, the VioSpor system was validated during several instrument inter-comparisons carried out under field conditions and VioSpor data were compared with the minimal erythema dose values obtained from spectroradiometer data, ${ }^{39}$ with a result of VioSpor accuracy of approximately $\pm 10 \%$. 
In our study, the personal cumulative solar erythemal UV exposure was measured with a VioSpor blue line dosimeter Type I. The hikers used one dosimeter per day placed on the top of their shoulder for the duration of their recreational day. The tennis players used one dosimeter per day from 10:00 am to 14:00 pm attached to Velcro straps on the wrist. The runners used four dosimeters during the study, placed on the wrist, each one being used in several consecutive races, depending on the distances of the races, as is shown in Table 2 .

\section{Ambient UV exposure}

Hiking group. For the two hikes in the province of Valencia, the ambient erythemal UVR was obtained from the Valencian regional government's (GV) UVB measurement network, ${ }^{40}$ which consists of five radiometers, one of which is located in the city of Valencia $\left(00^{\circ} 20^{\prime} 09^{\prime \prime} \mathrm{W} 39^{\circ} 27^{\prime} 49^{\prime \prime} \mathrm{N}\right.$, sea level), and another is located in Denia $\left(00^{\circ} 02^{\prime} 09^{\prime \prime} \mathrm{E} 38^{\circ} 49^{\prime} 19^{\prime \prime} \mathrm{N}, 44 \mathrm{~m}\right)$, on a flat roof without obstructions or shade. The radiometer is a model UVB-1 (Yankee Environment System, YES), which has a spectral range between 280 and $400 \mathrm{~nm}$ and a spectral response similar to the CIE erythemal action spectrum, ${ }^{36}$ and so this sensor is capable of measuring the biologically effective erythemal UVR. The calibration uncertainty was approximately $10 \%$, and consisted of a measurement of the spectral response of the radiometer indoors and a comparison with a Brewer MKIII spectroradiometer outdoors. ${ }^{41,42}$ The cosine error was less than $4 \%$ for solar zenith angles below $55^{\circ}$ (according to the manufacturer) and a double entry zenith angle-ozone calibration matrix was used for high zenith angles. ${ }^{41}$ The error given by the calibration matrix remained below $9 \%$ for zenith angles below $70^{\circ}$ for a constant ozone value of 300 Dobson Units (DU). Another calibration of this radiometer was performed by the Earth Physics Department of the Universitat de València by comparison with an 
Optronic OL-754 spectroradiometer fitted with a double monochromator with a spectral range from $250 \mathrm{~nm}$ to $800 \mathrm{~nm}$. The values obtained by the latter equipment were convolved with the CIE action spectrum ${ }^{36}$ and integrated and compared with the values given by the UVB- $1 .{ }^{43,44}$

For the other two hikes, the measurements were conducted in an area where there were no measuring devices available to measure ambient erythemal UV irradiance. Since this irradiance is necessary to calculate the exposure ratio, it was obtained for each day through simulations using the FastRT program, version $2.3 .{ }^{45}$ The input data for the simulations were: the geographical coordinates of the study site, the type of surface, the conditions of the sky and total column ozone. For each day, column ozone values were obtained from data provided by the Ozone Monitoring Instrument (OMI). ${ }^{46}$

Also, the ambient erythemal UVR for each day was obtained using satellite data from the OMI ${ }^{47}$ Erythemal daily dose (EDD) was produced with the Giovanni online data system, developed and maintained by the NASA GES DISC. ${ }^{48}$ The input data for the calculation were the geographical coordinates of the study site. The EDD obtained from OMI has been used only for comparison with that obtained with the two above procedures.

Tennis players and runners. Ambient erythemal UVR was obtained from the Valencia station GV UVB measurement network. ${ }^{40}$. For these groups the EDD from the $\mathrm{OMI}^{47}$ was also obtained and it has been compared with that from the GV UVB measurement network. $^{40}$

\section{UV exposure limits}


The International Commission on Non-Ionizing Radiation Protection (ICNIRP) ${ }^{49}$ recommends a maximum personal daily exposure of $30 \mathrm{~J} / \mathrm{m}^{2}$ effective $\mathrm{UV}$ dose, called the exposure limit (EL), within an 8-hour period for sensitive unprotected skin using the American Conference of Governmental Industrial Hygienists (ACGIH) action spectrum. The relationship between CIE and ACGIH weighted exposures depends on the time of day, solar zenith angle, ozone concentrations, etc. The relation considered in this paper between the two action spectra as shown in Moehrle et al. ${ }^{50}$ is: effective exposure CIE $=3.63 \cdot$ effective exposure $\mathrm{ACGIH}$, so that the equivalent effective exposure using $\mathrm{CIE}$ spectrum is $109 \mathrm{~J} / \mathrm{m}^{2}$ (1.1 SED) per workshift.

As reported by ICNRIP, ${ }^{49}$ skin subjected to frequent UV exposure not only tans but also thickens, and this thickening leads to a significant increase in UV protection by a factor of five or greater. This report ${ }^{49}$ considers a value of 12 SED to be the selfprotection factor of sun-adapted skin for Mediterranean subjects with skin phototype III, and a value of 5 SED for the same type of skin but without adaptation to the sun.

The measured exposure of athletes was compared with the value of 5 SED, since we were studying subjects with non sun-adapted skin type III, and it was also compared with the EL value.

The time of exposure necessary to exceed the EL was calculated for each day by means of a module of the FastRT program, version 1.2. ${ }^{51}$ The input data for the simulation, beyond those listed in a previous paragraph, were the start times of exposure for each day, as recorded on the questionnaires. For the runners, it was not calculated since the times at which competitions take place are away from solar noon.

\section{Ethics}


This study follows the guidelines set by the appropriate ethical committee of the Universitat Politècnica de València.

\section{Results}

\section{Ambient solar UVR}

The data of the daily ambient erythemal UVR and the corresponding maximum UV index (UVI) ${ }^{52,53}$ for the periods of the study are shown in Tables 1 and 2 . These tables also list the ozone data and EDD from the NASA OMI. ${ }^{46,47}$

\section{$<$ Table 2>}

Hiking group. It can be seen that the solar UVI for the summer months is quite high, from 9 to 12 on most days, normal for this time of year, except on day $3^{\text {rd }}$ it was cloudy. On July $3^{\text {rd }}$ the difference between OMI-derived EDD and ground measurements reaches $40 \%$, probably due to cloud conditions of this day. Several studies ${ }^{54,55}$ show that the variability of cloud conditions within the satellite pixel may result in high differences between OMI satellite and ground-based stations data. Regarding the UV dose simulated by FastRT program, the bias is between $+2 \%$ and $-10 \%$. The negative bias has been explained by several authors, since OMI underestimates the irradiance when surface presents a snow cover, because of the climatological surface albedo used by the OMI surface UV algorithm results in an overestimation of cloudiness. ${ }^{56,57}$ Tennis player group. The OMI-derived EDD overestimate Valencia ground- based measurements by $14-20 \%$, and these results are in agreement with previous studies ${ }^{56,57}$ because Valencia station is in an urban area, in which absorbing aerosols are not taken into accounted for in satellite UV algorithms so far. 
Runner group. The OMI-derived EDD, obtained for the geographical coordinates of the Valencia city, overestimate Valencia ground- based measurements by 1-40\% except in one location, $80 \mathrm{~km}$ from Valencia city, where OMI-derived EDD is lower by $40 \%$ than the EDD provided by the GV measurement network, probably due to overcast conditions on November $6^{\text {th }} \cdot 54,55$

\section{Measured UV exposures}

Hiking group. This group received a median daily UV exposure of 8.1 SED with a range of 19.5-1.8 SED, as shown in Table 3. The exposure ratio (ER) was defined as the ratio between the personal UV dose on a selected anatomical site and the 24 hours ambient UV dose on a horizontal plane on the same day of exposure. Median ER was $16.4 \%$ with a range of $33.5-8.9 \%$.

Table 3 displays the wide range of erythemal UV exposure for each day and it may be useful for consideration of the issue of whether the hikers behaved as a homogeneous group with respect to outdoor UV exposure.

Table 4 shows the exposure time ( $\mathrm{t}_{\mathrm{e}}$-UVR in minutes) to exceed ICNIRP exposure limit for the period of the study. It can be seen that a subject could stay in the sun between 16 and 76 minutes without exceed limit dose, depending of the start time of the activity. <Tables 3 and 4>

Tennis player group. The median daily UV exposure of this group was 7.5 SED, with a maximum of 13.8 SED and a minimum of 2.0 SED, as shown in Table 5. The ratio of the personal dose to ambient erythemal UVR yields an ER median value, as a percentage, of 15.0, ranging from 26.6 to 3.8 .

As can be seen in Table 6, a tennis player exceed EL dose in about 20 minutes. 
Runner group. The median UV exposure of this group during a running circuit was 14.6 SED, and the median hourly outdoor reading was 0.9 SED as shown in Table 7. Table 7 also lists the exposures recorded for each runner as a percentage of the daily total ambient erythemal UVR, and it was, for all runners, a median value of $5.8 \%$, ranging from 14.1 to $0.7 \% .<$ Table $7>$

Median daily UV exposure of all sports groups therefore exceeded the EL by a factor ranging from 2 to 7 , so that the persons engaged in these sports received between 2 and 7 times the expected occupational UVER load according ICNIRP limit ${ }^{49}$.

\section{Discussion}

In a comparison with similar studies, Moehrle et $a l .{ }^{25}$ found a mean daily personal exposure of 29.8 SED for mountain guides in several high altitude areas during the spring and summer, using a dosimeter attached laterally to the head, whereas we used a shoulder dosimeter position. We found a median daily exposure, in summer, of 8.1 SED, quite different to that of Moehrle et al. This could be due to the different dosimeter position, the higher altitude of the Moehrle et al. ${ }^{25}$ study area, and that the mountain guides were professionals who spent around 10 hours outdoors.

Allen and McKenzie ${ }^{58}$ found that the UV irradiance on horizontal surfaces in a ski resort was 20-30\% higher than at sea level and they also indicate that the exposures depended strongly on the time of year, which may explain part of the differences found with other papers.

In Tasmania (Australia), Herlihy et al. ${ }^{31}$ studied the UV exposure in summer for tennis players at seven anatomical sites. They obtained a mean daily UV exposure of 8.7 
SED for a hand dosimeter position, and we found a median daily exposure of 7.5 SED, which is similar.

In Valencia, Serrano et al. ${ }^{28}$ measured the UV exposure for several groups of sportsmen and women. In the previous study, for the hikers and for the tennis players, we found an ER of $21.7 \%$, and $11.9 \%$ respectively. In this study, we have recorded an ER of $16.4 \%$ for the hikers and the differences with the above study may be due to the different position of the dosimeters, and the different hike locations. For the tennis players, we have recorded an ER of $15 \%$, similar to the previous study. With respect to the runners, in the previous study we obtained an hourly outdoor reading of 0.6 SED, and a mean ER of $1.9 \%$. The differences with the results of this study are due to a different study design, as the first study considered the dose received during summer training periods, which took place in the evening.

With regard to the hiking group, some individuals received consistently higher or lower exposures than their companions, so that behaviour was not homogeneous for the group as a whole with respect to outdoor UV exposure. The observed variations of doses, ER and UVR, might be due to inter-individual variations of exposure angles of the dosimeters with respect to the sun. Moreover, the hikers did not always partake in activities in the same group. Therefore, fixation of the position of the dosimeter on the shoulder varied and dosimeters were not fixed at the same place or altitude or with the same exposure of the dosimeter to the sun and this may explain the variations.

As for the tennis players, they did not behave as a homogeneous group either with respect to outdoor UV exposure, with the coaches being those displaying less consistent behaviour. Given that the tennis players train in a bounded area, this was unexpected. This result may be due to the different orientation of the two tennis courts where the study took place, with the dosimeters therefore having different positions with respect to the sun on the 
same day and at the same time of exposure.

The median daily UV exposure of the hikers and tennis players (8.1 SED and 7.5 SED respectively) exceeded 5 SED, which means that in the case of non sun-adapted skin type III and non-use of sun protection, erythema may be induced in these individuals, indicating that protective measures such as high quality protection equipment and the use of sunscreens are absolutely necessary.

In addition, UV exposure exceeded the EL, so that the subjects engaged in these recreational/occupational activities received up to 8 times the recommended UV exposure for outdoor activities. The tennis players exceeded the EL within approximately 20 minutes every day of the measurement period. Regarding mountaineers, the start time of their activity is variable, resulting in a wide range of time before they exceeded the EL. On one day they exceeded the EL within 16 minutes but on another the EL was exceeded only after a period of 76 minutes. If the mountaineering activities are conducted near solar noon, the exposure dose limit recommended by ICNIRP is typically reached in about 20 minutes under these conditions.Although the measurements of the hikers and tennis players cannot be compared and this is not among the objectives of this study, the tennis players received higher doses per hour outdoors (2.0 versus $1.3 \mathrm{SED}$ ), calculated as the ratio between median UV exposure and the mean time spent outdoors. This may be due to the fact that they train in a bounded area without roofs or shade, while the hikers undertake their sport in the mountains, where there are many trees that provide shade.

It has been obtained that the OMI-derived EDD overestimate ground- based measurements of 1 to $25 \%$ in $80 \%$ of the days of the study, and these results are in concordance with previous studies obtained at other sites, ${ }^{56,57}$ except when there are variability of cloud conditions within the satellite pixel that may result in high differences between OMI satellite and ground-based data. ${ }^{54,55}$ 
The mean daily time of exposure of the hikers was 376 minutes, which exceeds the exposure times causing erythema on every day of the study, even for days with the highest time of exposure for sunburn to occur for persons with skin type IV (Table 4). With regard to the tennis players, the mean daily time of exposure was 240 minutes, which is almost four times the exposure time for erythema to occur for every day of the study for skin type III subjects (Table 6). According to these results, these sportsmen and women would suffer sunburn to their skin if they were not adequately protected when performing outdoor physical activities, which may potentially enhance the later risk of skin cancer.

With regard to the runners, we measured the dose received by them in the races in which they have participated as part of a running circuit. Since the circuit was composed of 12 races and the runners did not participate in all of them, we can compare neither the total dose received by each of them nor the range of UV exposure for each subject, but we can compare the dose received per hour of outdoor exposure. It is necessary to keep in mind that the circuit is composed of races taking place over a year, with their start time varying according to the time of the year, as well as the distance involved.

The runners received a median UV exposure of 2.1 SED per competition day and they did not reach the maximum personal exposure of 5 SED, probably because the running circuit takes place throughout a year and the races take place at about $7 \mathrm{pm}$ in the summer season due to the hot weather. We calculated the doses according to the time of the year, with a median dose received in the autumn and the summer being similar, around 1.3 SED, whereas in the spring the runners suffered an increased exposure of 2.2 SED (these data are not listed in the tables). This increased exposure could be attributed to the fact that, in the spring, a season in which there may be hot days, the races were held in the morning. It should also be noted that the measurements have a $10 \%$ error, according to the 
manufacturer's own information.

\section{Conclusion}

According to the results, these sportsmen and women can spend up to nine hours per day exposed to UVR during their summer recreational/training activities, damaging their skin and causing erythema, and potentially increasing the later risk of skin cancer. It must also be taken into account that it is difficult for groups who undertake their activities at midday (the hikers and tennis players) to avoid UV exposure. These results emphasise the need to undertake protective measures against solar radiation, such as using high protection sunscreen (30 or higher), sunglasses, hats and high quality protective equipment, when performing physical activities outdoors. Balancing the dual needs of protective clothing and of transpiration and body cooling in outdoor sports is known to be difficult. Accordingly, it is necessary to encourage the use of high protection sunscreens.

This information has been sent to the sports groups participating in this study in order to make them aware of the radiation they received and so that they might reduce the level of this by taking appropriate protective measures.

In conclusion, a personal VioSpor film dosimeter was used to measure the UV exposure of some groups of sportsmen and women, and we found that, for two of these groups, the international UV threshold level for non sun-adapted Mediterranean skin was exceeded. 


\section{Acknowledgments}

The authors wish to thank the members of the hiking group, the UPV athletics club, and the tennis club for their cooperation in this study. We would also like to thank the National Meteorology Agency and the Generalitat Valenciana for providing us with access to meteorological data.

We acknowledge the NASA mission scientists and Principal Investigators who provided data used in this paper, produced with the Giovanni online data system, developed and maintained by the NASA GES DISC.

This research was supported by the Spanish Ministry of Education and Science as part of research project CGL2010-15931 and the Generalitat Valenciana as part of project PROMETEO/2010/064. 


\section{References}

1 L.R. Sklar, F. Almutawa, H.W. Lim and I. Hamzavi, Effects of ultraviolet radiation, visible light, and infrared radiation on erythema and pigmentation: a review, Photochem. Photobiol. Sci., 2013, 12, 54-64.

2 M. Norval, R.M.Lucas, P. Cullen, F.R. de Gruijl, J. Longstreth, Y. Takizawa and J.C. van der Leung, The human health effects of ozone depletion and interactions with climate change, Photochem. Photobiol. Sci., 2011, 10, 199-225.

3 R. Lucas, A.J. McMichael, B. Armstrong and W. Smith, Estimating the global disease burden due to ultraviolet radiation exposure, International Journal of Epidemiology, 2008, 37, 654-67.

4 A. Juzeniene, P. Brekke A. Dahlback A, S. Andersson-Engels, J. Reichrath, K. Moan, M.F. Holick, W.B. Grant and J. Moan, Solar radiation and human health, Rep. Prog. Phys., 2011, 74, 066701 (56pp).

5 F.R. De Gruijl, Sufficient Vitamin D from Casual Sun Exposure?, Photochemistry and Photobiology, 2011, 87, 598-601.

6 A.R. Webb, R. Kift, J.L. Berry and L.E. Rhodes, The Vitamin D Debate: Translating Controlled Experiments into Reality for Human Sun Exposure Times, Photochemistry and Photobiology, 2011, 87, 741-5. 
7 M. Norval, A.P. Cullen, F. De Gruijl, J. Longstreth, Y. Takizawa, R.M. Lucas, et al., The effects on human health from stratospheric ozone depletion and its interactions with climate change, Photochem. Photobiol. Sci., 2007, 6, 232-51.

8 M.T. Kampman and L.H. Steffense, The role of vitamin D in multiple sclerosis, Journal of Photochemistry and Photobiology B: Biology, 2010, 101, 137-41.

9 A. Zittermann and J.F. Gummert, Sun, vitamin D, and cardiovascular disease, Journal of Photochemistry and Photobiology B: Biology, 2010, 101, 124-9.

10 W.B. Grant, Relation between prediagnostic serum 25-hydroxyvitamin D level and incidence of breast, colorectal, and other cancers, Journal of Photochemistry and Photobiology B: Biology, 2010, 101, 130-6.

11 D.D. Bikle, Protective actions of vitamin D in UVB induced skin cancer, Photochem. Photobiol. Sci., 2012, 11, 1808-16.

12 M.B. Humble, Vitamin D, light and mental health, Journal of Photochemistry and Photobiology B: Biology, 2010, 101, 142-9.

13 A. Cabanes, B. Pérez-Gómez, N. Aragonés, M. Pollán and G. López-Abente, La situación del cáncer en España, 1975-2006, Instituto de Salud Carlos III, Ministerio de Ciencia e Innovación, Madrid 2009. 
14 E. de Vries, J.E. Tyczynski, D. Maxwell Parkin, Cutaneous malignant melanoma in Europe, European network of cancer registries. International agency for research on cancer, ENCR CANCER FACT SHEETS N No 4, November 2003.

15 C. Garbe and U. Leiter, Melanoma epidemiology and trends, Clinics in Dermatology, 2009, 27, 3-9.

16 V. Madan, J. Lear and R.M. Szeimies, Non-melanoma skin cancer, Seminar ww.thelancet.com., February 20 2010, 375, 673-85.

17 World Health Organization, World Cancer Report 2008, International Agency for Research on Cancer, Edited by Peter Boyle and Bernard Levin, Lyon 2008.

18 Cáncer en cifras, Centro Nacional de Epidemiología Instituto de Salud Carlos III, Available at http://193.146.50.130/morta/grafs.php\#grafs, [accessed 1-10-12].

19 A.J. Stratigos, A.M. Forsea, R.J.T. van der Leest, E. de Vries, E. Nagore, J.L. BulliardL, M. Trakatelli, J. Paoli, K. Peris, J. Hercogova, M. Bylaite, T. Maselis, O. Correia and V. del Marmol, Euromelanoma: a dermatology-led European campaign against nonmelanoma skin cancer and cutaneous melanoma. Past, present and future, British Journal of Dermatology, 2012, 167, 99-104.

20 C.M. Ambros-Rudolph, R. Hofmann, E. Richtig, M. Muller, H.P. Soyer and H. Kerl, Malignant Melanoma in Marathon Runners, Arch. Dermatol., 2006, 142, 1471-4. 
21 E. Richtig, C.M. Ambros-Rudolph, M. Trapp, J.K. Lackner, R. Hofmann-Wellenhof, H. Kerl and G. Schwaberger, Melanoma Markers in Marathon Runners: Increase with Sun Exposure and Physical Strain, Dermatology, 2008, 217, 38-44.

22 H. Williams, J. Brett and A. Du Vivier, Cyclist's melanoma, J. of the Royal College of Phys. Of London, 1989, 23(2), 114-5.

23 V. Lichte, B. Dennenmoser, K. Dietz, H.M. Hafner, B. Schlagenhauff, C. Garbe, J. Fischer and M. Moehrle, Professional risk for skin cancer development in male mountain guides - a cross-sectional study, JEADV, 2010, 24, 797-804.

24 N.J. Downs, A.V. Parisi and P. Schouten, Basal and squamous cell carcinoma risks for golfers: An assessment of the influence of tee time for latitudes in the Northern and Southern hemispheres, Journal of Photochemistry and Photobiology B: Biology, 2011, 105, 98-105.

25 M. Moehrle, M. Korn and C. Garbe, Bacillus subtilis spore film dosimeters in personal dosimetry for occupational solar ultraviolet exposure, Int Arch Occup Environ Health, 2000, 173, 575-80.

26 E.G. Rigel, M.G. Lebwohl, A.C. Rigel ans D.S. Rigel, Ultraviolet radiation in Alpine skiing, Arch. Dermato., 2003, 139, 60-2. 
27 A.M. Siani, G.R. Casale, H. Diémoz, G. Agnesod, M.G. Kimlin, C.A. Lang and A. Colosimo, Personal UV exposure in high albedo alpine sites, Atmos. Chem. Phys., 2008, 8, 3749-60.

28 M.A. Serrano, J. Cañada and J.C. Moreno, Ultraviolet exposure for different outdoor sports in Valencia, Spain, Photodermatology, Photoimmunology \& Photomedicine, 2011, 27, 311-7.

29 M. Moehrle, L. Heinrich, A. Schmid and C. Garbe, Extreme UV exposure of professional Cyclists, Dermatology, 2000, 201, 44-5.

30 M.A. Serrano, J. Cañada and J.C. Moreno, Erythemal Ultraviolet exposure of cyclists in Valencia, Spain, Photochemistry and Photobiology, 2010, 86, 716-21.

31 E. Herlihy, H.P. Gies, C.R.Roy and M. Jones, Personal dosimetry of solar UVR for different outdoor activities, Photochem Photobiol., 1994, 60, 288-94.

32 Biosense Laboratories, Available at www.biosense.de/home-e.htm, [accessed 16-0113].

33 M.A. Serrano, J. Cañada and J.C. Moreno, Erythemal Ultraviolet exposure in two groups of outdoor workers in Valencia, Spain, Photochemistry and Photobiology, 2009, 85, 1468-73. 
34 Y. Furusawa, L.E. Quintern, H. Holtschmidt, P. Koepke and M. Saito, Determination of erythema-effective solar radiation in Japan and Germany with a spore monolayer film optimized for the detection of UVA and UVA - results of a field campaign, Appl. Microbiol. Biotechnol., 1998, 50, 597-603.

35 N. Munakata, S. Kazadzis, A.F. Bais, K. Hieda, G. Ronto, P. Rettberg and G. Horneck, Comparisons of Spore Dosimetry and Spectral Photometry of Solar-UV Radiation at Four Sites in Japan and Europe, Photochemistry and Photobiology, 2000, 72(6), 739-45.

36 C.I.E.Commission Internationale de l'Eclairage (1998) Erythema Reference Action Spectrum and Standard Erythema Dose. CIE S007E-1998. CIE Central Bureau, Vienna, Austria.

37 CIE, International Commission on Illumination, Standard Erythema Dose, a Review, CIE Journal 1997, 125, Vienna.

38 L.E. Quintern, Y. Furusawa, K. Fukutsu and H. Holtschimdt, Characterization and application of UV detector spore-films: the sensitivity curve of a new detector system provides good similarity to the action spectrum for UV-induced erythema in human skin, J. Photochem. Photobiol. B:Biology, 1997, 37, 158-66.

39 G. Seckmeyer, B. Mayer and G. Bernhard, The 1997 Status of Solar UV Spectroradiometry in Germany: Results from the National Intercomparison of UV Spectroradiometers, with contributions from Albold A., Baum W., Dehne K., 
Feister U.,Gericke K., Grewe R., Gross C., Sandmann H., Schreiber J., Seidlitz

H.K., Steinmetz M., Thiel S., Wallasch M. and Weller M.. Garmisch-

Partenkirchen, Germany, Fraunhofer Institute for Atmospheric Environmental

research 1998, 55/98, ISBN: 3-8265-3695-9.

40 Programa meteorología de la Fundación Centro de Estudios Ambientales del Mediterráneo (Generalitat Valenciana). Available at http://www.gva.es/ceamet/vigilancia/radUV/radUV.html; [accessed 2-07-12]

41 J.M. Vilaplana, V.E. Cachorro, M. Sorribas, E. Luccini, A.M.de Frutos, A. Berjón and B. de la Morera, Modified calibration procedures for a Yankee Environmental System UVB-1 biometer based on spectral measurements with a Brewer spectrophotometer, J Photochem Photobiol 2006, 82, 508-14.

42 G. Hülsen and J.Gröbner, Characterization and calibration of ultraviolet broadband radiometers measuring erythemally weighted irradiance, App. Opt. 2007, 46, 587786.

43 J. Cañada, A.R. Esteve, M.J. Mari, M.P. Utrillas, F. Tena and J.A. Martinez-Lozano, Study of erythemal, UV(A+B) and global solar radiation in Valencia (Spain), International Journal of Climatology, 2008, 28, 693-702.

44 F. Tena, J.A. Martinez-Lozano, M.P. Utrillas, M.J. Marin, A.R. Esteve and J., Cañada, The erythemal clearness index for Valencia, Spain, International Journal of Climatology 2009, 29, 147-55. 
45 O. Engelsen and A. Kylling, Fast simulation tool for ultraviolet radiation at the Earth's surface, Optical Engineering, 2005, 44 (4), 041012 doi: 10.1117/1.1885472, Available at

http:/ / nadir.nilu.no / olaeng / fastrt / fastrt.html, [accessed 04-06-12].

46 NASA. Ozone Monitoring Instrument. Available at http://ozoneaq.gsfc.nasa.gov/ozone_overhead_all_v8.md, [accessed 05-06-12].

47 OMI/Aura Online Visualization and Analysis. Daily Level 3 Global Gridded Products. Available at http://gdata1.sci.gsfc.nasa.gov/daacbin/G3/gui.cgi?instance $\mathrm{id}=\mathrm{omi}$, [accessed 10-07-13].

48 J. G. Acker and G. Leptoukh, Online Analysis Enhances Use of NASA Earth Science Data, Eos, Trans. AGU 2007, 88( 2), 14-17.

49 International Commission on Non-Ionizing Radiation Protection (ICNIRP), Protection of Workers against Ultraviolet Radiation, Health Physics, 2010, 99 (1), 66-87.

50 M. Moehrle, B. Dennenmoser and C. Garbe, Continuous long-term monitoring of UV radiation in Professional mountain guides reveals extremely high exposure, Int. J. Cancer, 2003, 103, 775-8. 
51 A.R. Webb and O. Engelsen, Calculated Ultraviolet Exposure Levels for a Healthy Vitamin D Status, Photochemistry and Photobiology 2006, 82(6), 1697-1703. Available at http://nadir.nilu.no/ olaeng/fastrt/VitD_quartMEDandMED_v2.html [accessed 05-11-12].

52 ICNIRP (International Commission on Non-Ionizing Radiation Protection) Global Solar UV Index. ICNIRP-1/95, Oberschleissheim, Germany.

53 World Health Organization. Global Solar UV Index: A Practical guide, WHO 2002, Geneva, Switzerland.

54 P. Weihs, M. Blumthaler, H.E. Rieder, A. Kreuter, S. Simic, W. Laube, A.W. Schmalwieser, J.E. Wagner and A. Tanskanen, Measurements of UV irradiance within the area of one satellite pixel, Atmos. Chem. Phys., 2008, 8, 5615-5626. http://www.atmos-chem-phys.net/8/5615/2008/.

55 S. Kazadzis, A. Bais, D. Balis, N. Kouremeti, M. Zempila, A. Arola, E. Giannakaki, V. Amiridisand A. Kazantzidis, Spatial and temporal UV irradiance and aerosol variability within the area of an OMI satellite pixel, Atmos. Chem. Phys., 2009, 9, 4593-601. www.atmos-chem-phys.net/9/4593/2009/

56 A. Tanskanen, A.Lindfors, A. Maatta, N. Krotkov, J. Herman, J. Kaurola, T. Koskela, K. Lakkala, V. Fioletov, G. Bernhard, R. McKenzie, Y. Kondo, M. O’Neill, H. Slaper, P. den Outer, A. Bais, and J. Tamminen, Validation of daily erythemal doses from ozone monitoring Instrument with groundbased UV 
measurement data, J. Geophys. Res., 2007, 112, D24S44,

doi:10.1029/2007JD008830.

57 V. Buchard, C. Brogniez, F. Auriol, B. Bonnel, J. Lenoble, A. Tanskanen, B. Bojkov, and P. Veefkind, Comparison of OMI ozone and UV irradiance data with groundbased measurements at two French sites, Atmos. Chem. Phys., 2008, 8, 4517-4528.

58 M. Allen and R. McKenzie, Enhanced UV exposure on a ski-field compared with exposures at sea level, Photochem. Photobiol. Sci., 2005, 4, 429-37. 